\title{
Menemismo y kirchnerismo frente al gasto estatal en educación y seguridad*
}

\author{
Menem, Kirchner and Government Expenditure on \\ Education and Security
}

\section{Menemismo e kirchnerismo frente ao gasto estadual na educação e seguridade}

Mauro Cristeche** - Argentina

Recibido el 28 de febrero de 2012, aceptado el 16 de abril de 2012

\section{Resumen}

Objetivos: analizar la educación y la seguridad estatales en Argentina a partir del gasto público durante los gobiernos de Carlos Menem (1989-1999) y Néstor Kirchner (2003-2007). Metodología: investigación documental que tomó como fuente principal la "Serie de Gasto Público Consolidado por finalidad y función (1980-2008)" del Ministerio de Economía de la Nación, actualizada a julio de 2010. La evolución del Producto Interno Bruto a valores constantes surge de un cálculo propio. Se muestran los datos entre 1980 y 2008 para observar el auge y la caída del "modelo neoliberal" y el retorno a la estrategia estatal, y observar los momentos de crisis económicas. Resultados: a diferencia de las posiciones dominantes en torno a la cuestión, se observó que el Estado argentino no "desapareció" en la década del 90, en términos de financiamiento de los rubros analizados. En educación, el gasto estatal ha crecido considerablemente, multiplicando por tres su participación en el Producto Interno Bruto. Defensa y seguridad, por el contrario, pierde peso relativo frente a otros rubros. La "descentralización" es un fenómeno que atañe a ambos rubros. Conclusiones: el gasto público depende de la capacidad recaudadora del Estado y, por tanto, de la situación general de la economía. El análisis de los períodos de crisis económica y la correspondiente caída del gasto público manifiesta que no tiene un comportamiento anti-cíclico. En el largo plazo, la participación del Estado en la economía ha crecido, pero se desploma ante las crisis.

Palabras claves: Estado, gasto público, educación, seguridad, crisis.

* Este trabajo es producto del desarrollo de la tesis doctoral "Estado, relaciones jurídicas públicas y reproducción social en Argentina. Acumulación de capital y Gasto público estatal (1980-2010)” desarrollada en el marco de las Becas de Posgrado Tipo I y II, otorgadas en 2008 y 2011, respectivamente, por el Consejo Nacional de Investigaciones Científicas y Técnicas, Ministerio de Ciencia, Tecnología e Innovación Productiva, Argentina.

** Doctorando en Derecho de la Universidad de Buenos Aires. Abogado. Docente Facultad de Ciencias Jurídicas y Sociales, Universidad Nacional de La Plata (Argentina). maurocristeche@yahoo.com.ar.

Para citar este artículo:
Cristeche, M. (julio - diciembre 2012). Menemismo y kirchnerismo frente al gasto estatal en educación y seguridad. Ánfora 19 (33), 31-49. Universidad Autónoma de Manizales. ISSN 0121-6538. 


\section{Abstract}

Objectives: To analyze state education and security in Argentina from the perspective of public expenditure during the administrations of Carlos Menem (1989-1999) and Nestor Kirchner (2003-2007). Methodology: A desk based research methodology was employed using "The Public Expenditure Series consolidated according to purpose and function (1980-2008)" of the Ministry of National Economics, updated in July 2010, as the main source. The evolution of Gross Domestic Product at constant values arises from investigator's own calculation. Data from the years 1980 to 2008 shows the rise and fall of "neoliberalism" and the return to a state strategy and also the times of economic crises. Results: In contrast to dominant positions on this issue, it was observed that the Argentine government did not "disappear" in the 90's in terms of funding the analyzed expenses. In education, state expenditure has grown considerably, increasing to three times its share of the Gross Domestic Product. In contrast, defense and security has lost importance when compared to other expenditures. The "decentralization" is a phenomenon that involves both expenditures. Conclusions: Public expenditure depends on the capacity of the state to collect it and therefore, on the overall economic situation. The analysis of periods of economic crisis and the corresponding fall in public expenditure show that there is no anti-cyclical behavior. In the long term, the state's participation in the economy has grown, although it falls in times of crisis.

Keywords: state, public expenditure, education, security, crisis

\section{Resumo}

Objetivos: analisar a educação e a segurança estadual na Argentina a partir do gasto publica durante os governos de Carlos Menem (1989-1999) e Nestor Kirchner (2003-2007). Metodologia: pesquisa documental que tomou como fonte principal a "Serie de Gasto Público Consolidado" por finalidade e função (1980-2008)" do Ministério de Economia da Nação; atualizada a julho a de 2010. A evolução do Produto Interno Bruto a valores constantes surge dum calculo próprio. Amostram se os dados entre 1980 e 2008 para observar o auge e a caída do "modelo neoliberal" e o retorno à estratégia estadual, e observar os momentos de crise econômicas. Resultados: a diferença das posições dominantes em torno à questão, observou se que o Estado argentino não “desapareceu” na década 90, em términos de financiamento dos rubros analisados. Em educação, o gasto estadual tem crescido consideravelmente, multiplicando por três sua participação no Produto Interno Bruto. Defensa e segurança, pelo contrario, perde peso relativo frente a outros rubros. A "descentralização" é um fenômeno que corresponde a ambos rubros. Conclusões: O gasto público depende da capacidade arrecadadora do Estado e, por tanto da situação geral da economia. O análise dos períodos de crise econômica e a correspondente caída do gasto publico manifesta que não tem um comportamento anticíclico. No ancho prazo, a participação do Estado na economia tem crescido, mas desapruma se ante a as crises.

Palavras chaves: Estado, gasto público, educação, segurança, crise

Para

citar este artículo:
Cristeche, M. (julio - diciembre 2012). Menemismo y kirchnerismo frente al gasto estatal en educación y seguridad. Ánfora 19 (33), 31-49. Universidad Autónoma de Manizales. ISSN 0121-6538. 


\section{Introducción}

La discusión sobre la importancia del Estado como sujeto central en la realidad social ha recobrado fuerza en los últimos años. Y en Argentina de manera notable. El papel que han asumido los Estados nacionales en Europa, en el marco de la crisis mundial en curso, ha puesto en completa evidencia el carácter puramente ideológico de las profecías que anunciaban, nada más y nada menos, la 'desaparición del Estado'. La desesperada intervención de los principales Estados del mundo en pos de sortear las consecuencias de la crisis, debería haber saldado esa discusión.

El fenómeno denominado 'neoliberalismo' (o ‘capitalismo neoliberal'), que ocupó la escena en el último cuarto del siglo XX, habría tenido como una de sus principales características el retiro del Estado de la vida económica, dando lugar al más crudo 'libre mercado'. Consecuentemente, la generalidad de los autores críticos del neoliberalismo ha pedido a gritos la 'reaparición' del desaparecido (Basualdo, 2002 y 2010). La respuesta a la miseria generada y generalizada por un nuevo período de acumulación de capital que se abrió, particularmente en Argentina, a mediados de los 70, habría de ser la 'vuelta al Estado' (Thwaites, 1999 y 2003).

En Argentina el fenómeno tiene nombre y apellido. Si bien se identifica el comienzo de la "etapa neoliberal" con el advenimiento de la dictadura militar en marzo de 1976, la gestión de Carlos Menem, con 10 años continuados al mando del gobierno nacional, habría sido la responsable de la disolución del Estado y de habilitar el pleno predominio del libre mercado (Basualdo, 2010; Koenig, 2009; Selva e Iñiguez, 2009). Una mirada exactamente antitética es la que predomina sobre el gobierno Kirchner. Es decir, el "matrimonio presidencial" habría venido a romper con la oleada neoliberal, a recuperar el terreno perdido por el Estado frente al mercado y, en consecuencia, a desplegar políticas económico-sociales con el objeto de atenuar los efectos de 3 décadas de neoliberalismo en Argentina (Selva e Iñiguez, 2009; Ferreres, 2011).

Una deficiencia de los estudios sobre el fenómeno es quizá el sobredimensionamiento de la intervención estatal pos crisis de 2001 (Oszlak, 2009), sin observar la "onda larga”, vale decir el movimiento en el mediano y largo plazo (Boyer y Neffa, 2004). Si se afirma un cambio de tendencia pos 2001, con el abandono de las 'recetas neoliberales', es necesario observar la dinámica del comportamiento económico del Estado por lo menos en los últimos 30 años ('Toledo y Neffa, 2008). Lo que se evidencia es un movimiento general ascendente de la participación estatal en la economía, tanto en términos de crecimiento relativo del gasto público, como de su participación en el PBI (Bulacio, 2003; Cristeche, 2010 y 2012). El gran problema han sido las crisis económicas (1982, 1989, 2001), que han puesto en cuestión la posibilidad de un crecimiento sostenido de la economía nacional y del Estado (Filc, 2008; Ferreres, 2011). Por eso la necesidad de la serie larga que utilizamos en este trabajo. 
Por otro lado, la idea de la retirada del Estado no ha sido apoyada con evidencias empíricas (Seiffer, 2010 y 2011). Se ha generado una suerte de imagen incontrastable, principalmente en el sentido común, pero también en los ámbitos académicos, que carece de estudios rigurosos que la sustenten, aunque dicha imagen ha comenzado a revertirse en el último tiempo. El presente trabajo tiene por objeto acercar la mirada a dos aspectos trascendentales de la vida social: la educación y la seguridad estatales en Argentina. Ello, a partir del análisis del Gasto Público estatal en tales rubros, durante los dos gobiernos más influyentes y paradigmáticos desde la reapertura democrática, en 1983: el de Carlos Menem (1989-1999) y el de Néstor Kirchner (2003-2007). La propuesta persigue visualizar las 'continuidades' y 'rupturas' entre dos modelos que se presentan como antagónicos, y presentar las determinaciones del gasto público más allá de lo político-ideológico, discutiendo con la mirada que le otorga una excesiva importancia a las voluntades políticas.

A su vez, se trata de un avance de la tesis doctoral del autor, que tiene un objetivo más general, precedido por un interrogante concreto: ¿en qué gasta el Estado?, que busca comprender las transformaciones del Estado como forma concreta de la acumulación de capital en Argentina, a partir de la evolución del Gasto Público, en el período 1980-2008.

\section{Metodología}

En este trabajo se toma como fuente principal de análisis la "Serie de Gasto Público Consolidado por finalidad-función (1980-2008)" elaborado por la Dirección de Análisis de Gasto Público y Programas Sociales de la Secretaría de Política Económica, Ministerio de Economía de la Nación, tomando los períodos que incumben a este trabajo. Dicha fuente comporta la ventaja de trabajar con el conjunto del Gasto Público de los tres niveles de gobierno: a) Gobierno Nacional; b) Gobiernos Provinciales y Gobierno de la Ciudad Autónoma de Buenos Aires; y c) Gobiernos Municipales. A ello se considera como Gasto Público Total, independientemente del nivel de la estructura del Estado que efectúa el gasto (Bonari, 2007). No obstante, se hará alguna consideración sobre la descentralización de funciones y partidas en las áreas objeto del trabajo.

El Universo que se computa para establecer el Gasto Público Consolidado (GPC) incluye las erogaciones (corrientes y de capital) del Sector Público No Financiero, independientemente de si se encuentran registradas o no en los respectivos presupuestos (gastos "extrapresupuestarios"), sumando todos los niveles.

Se utilizará la serie de GPC en valores constantes. Para ello, la fuente se realiza corrigiendo los valores corrientes con un índice de precios combinado, constituido como un promedio simple del índice de precios mayoristas nivel general y el índice de precios al consumidor, ambos del INDEC. Se utilizó como base para el promedio el año 2001. Para la serie en porcentajes del PBI, se utilizó la serie de PBI base 1993. La evolución

34 del PBI a valores constantes, que no aparece en la fuente, se efectuó multiplicando el

Para citar este artículo:
Cristeche, M. (julio - diciembre 2012). Menemismo y kirchnerismo frente al gasto estatal en educación y seguridad. Ánfora 19 (33), 31-49. Universidad Autónoma de Manizales. ISSN 0121-6538. 
Gasto Público Total de cada año por cien, y luego dividiendo el resultado por el porcentaje de participación del GPT en el PBI.

Otra ventaja de la fuente utilizada es, precisamente, que otorga uniformidad al Gasto Público en cuanto a la finalidad-función, esto es, hace abstracción del nombre circunstancial que hayan recibido los diferentes destinos a lo largo del período (Selva e Iñiguez, 2009, p. 3). La última actualización de la Serie, según aparece en la página web de la Secretaría de Política Económica del Ministerio de Economía y Finanzas Públicas, se hizo en julio de 2010. No obstante, aparece indicado que todos los datos que se consignan para el año 2008 son cifras provisionales.

Finalmente, se ha optado por mostrar los datos de todos los años tomados aquí. Esto es, desde 1980 hasta 2008. Ello permitirá, por un lado, observar casi todo el período de, se supone, auge y caída del "modelo neoliberal" y el retorno a la estrategia estatal y, por otro, posibilitará el encuentro de rupturas y continuidades independientes a los gobiernos.

\section{Resultados}

\section{El Estado y el Gasto Público}

Es necesario, en primera instancia, poner en contexto el objeto específico de análisis. No es posible establecer la magnitud del gasto en educación y seguridad, si previamente no se los ubica en el ámbito general del gasto estatal e, incluso, si no se considera la magnitud del gasto estatal dentro de la economía argentina. Por lo tanto, se comenzará analizando la participación del Gasto Público Total (GPT) en el PBI. Así, en el Gráfico 1 se puede observar la evolución del PBI y del GPT durante el período bajo análisis.

\section{Gráfico 1}

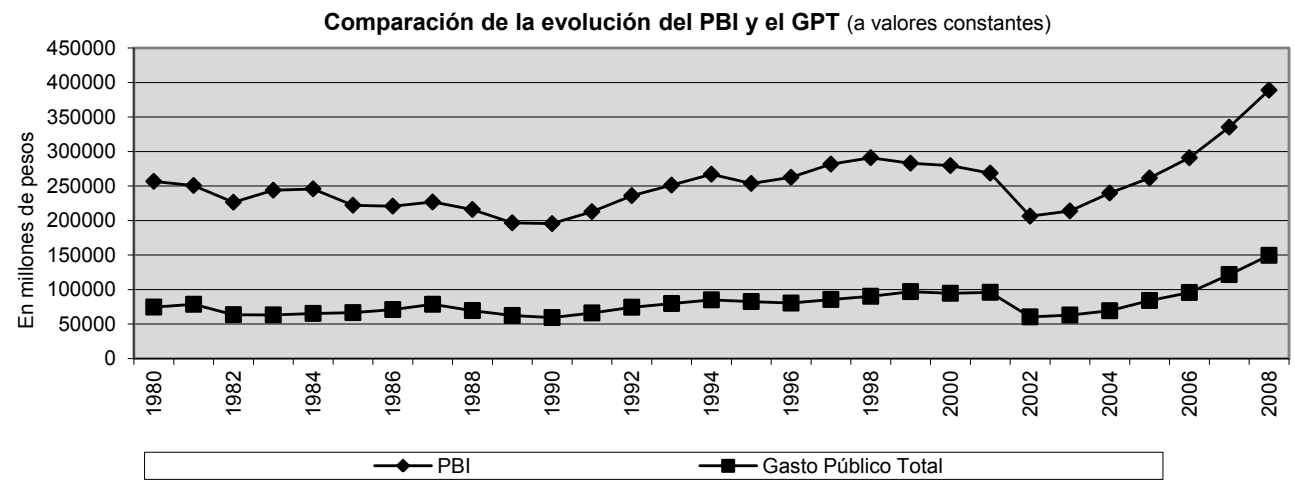

Fuente: elaboración propia con base en datos de la Secretaría de Política Económica, MEcon. Cálculo del PBI propio con base en datos de GPC y \% del PBI de la SPE, MEcon. 
El PBI argentino ha crecido casi un 60\% tomando todo el período 1980-2008. Se observa que el movimiento de la curva no es uniforme. Precisamente, lo que expresa son los efectos que sobre aquél han tenido las crisis internacionales y su manifestación nacional en los últimos 30 años. Así, en 1980 el PBI es de unos 256 mil millones de pesos. La crisis del 82 lo hace caer unos 30 mil millones; desde ahí, no logra alcanzar el punto de partida hasta 1994. La década del 80 es prácticamente caída, que desemboca en el PBI más bajo del período, en 1990: 195 mil millones. En los 90 crece lentamente, con algún tropiezo, hasta alcanzar su punto más alto en 1998: 290 mil millones. Luego se avizora la crisis de 2001, que lo hace desplomar en 2002: 206 mil millones, es decir, cae casi el 30\% en sólo cuatro años. Se recupera a partir de ese momento, y en 2005 logra superar los valores de 1980. Finalmente, por lo menos hasta el último año analizado, se evidencia un crecimiento sostenido a partir de 2002. En efecto, en los últimos seis años del período, casi se ha multiplicado por 2 . Y seguramente la tendencia sea la misma en los siguientes hasta la actualidad.

Luego, es posible observar cómo la curva del PBI determina la del GPT. Más adelante se verá con detenimiento el comportamiento de ésta última.

Ahora hay que mirar la evolución de la participación del GPT, del Gasto en Funcionamiento del Estado (FE) y del Gasto Público Social (GPS) en el PBI.

\section{Gráfico 2}

\section{Evolución del GPT, GPS y FE en el PBI (en \%)}

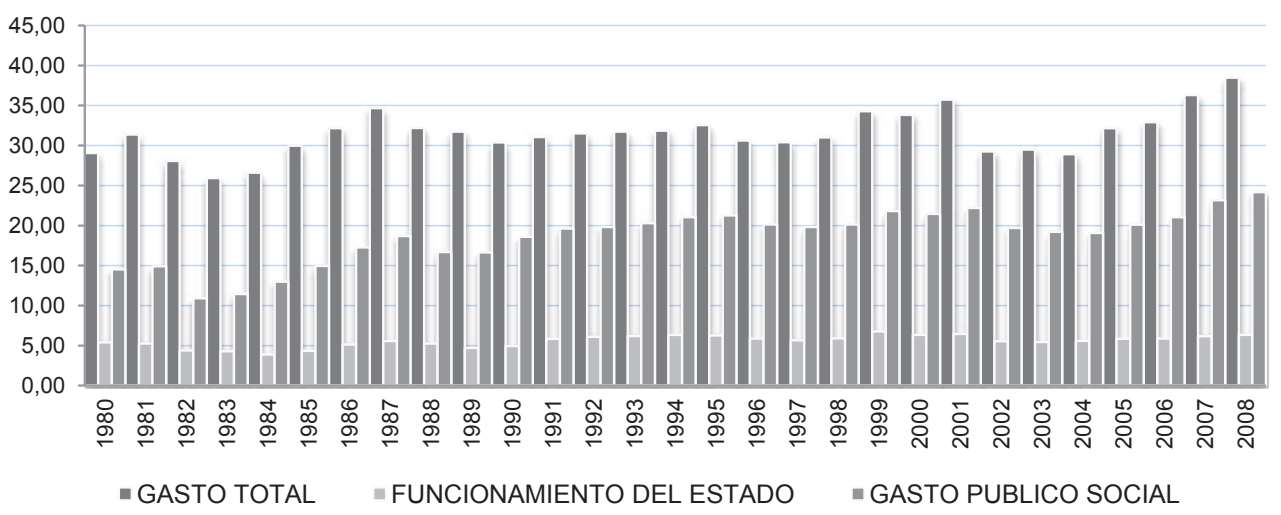

Fuente: elaboración propia con base en datos de la Secretaría de Política Económica, MEcon.

El Gasto Público Total (GPT) ha crecido casi 10 puntos en su participación en el PBI. Al comienzo del período, en 1980, su participación significa el 29\% del PBI, mientras que en 2008 significa el 38,5\%. No se muestra ninguna caída brusca, a excepción de 2002, en el que cae 6 puntos en relación con 2001, y lo hace retroceder al punto de partida. Incluso en 2004 la participación del GPT en el PBI era inferior a 1980. Duran- 
te la década del 90, su participación se mantiene prácticamente constante. Al comienzo del Menemismo, en 1989, significa casi el 32\%, mientras que en 1999 supera el 34\%. Este último porcentaje, constituye a su vez el promedio del período, lo cual sirve para desnudar la idea -inconsistente- que ha hecho carne en la opinión pública: la 'desaparición del Estado’ durante el menemismo. Finalmente, la evolución del GPT en relación con su participación en el PBI durante el período, implica un crecimiento del 33\%.

Es importante el análisis del Gasto Público Social (GPS), ya que es el destino general dentro del cual se encuentra el rubro Educación, Cultura y Ciencia y Tecnología. En términos porcentuales, el GPS ha crecido más en su participación en el PBI, que el GPT. En efecto, los 10 puntos que ha crecido el GPT, han sido absorbidos por el GPS. Así, éste pasó de absorber menos del 15\% del PBI en 1980, a casi el 25\% en 2008, lo cual redunda en un crecimiento del 66\%. Por el contrario, la participación en el PBI de los otros tres destinos generales, se ha mantenido constante.

Es el caso del rubro Funcionamiento del Estado (FE), en el que se encuentra el de Defensa y Seguridad. En cuanto al porcentaje de participación en el PBI, FE se ha mantenido relativamente constante desde los 80 a esta parte. Paradójicamente, su mayor participación se produce en el año 1999, el último del Gobierno de Menem, en el que alcanza el 6,75\% del PBI. El porcentaje más bajo se registra en 1984, cuando tiene una participación del 3,86\%. En 1989, cuando comienza el menemismo, FE alcanza el 4,69\% del PBI. Quiere decir que en los 10 años de Menem logró un movimiento ascendente de 2 puntos del PBI. Ello redunda en un crecimiento de FE en el PBI superior al 30\% en los 90 . Tomando el período en su conjunto, FE tuvo un crecimiento inferior al 15\%.

Ahora, se hace necesario revisar la evolución del GPT, el FE y el GPS a valores constantes.

\section{Gráfico 3}

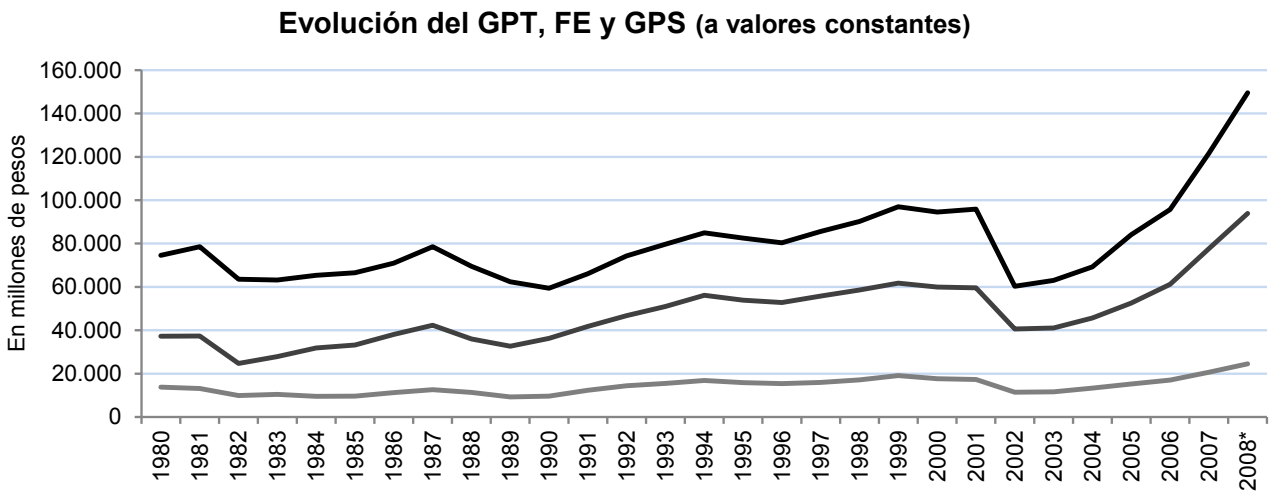

— GASTO TOTAL — — FUNCIONAMIENTO DEL ESTADO — GASTO PUBLICO SOCIAL

Fuente: elaboración propia con base en datos de la Secretaría de Política Económica, MEcon. 
A valores constantes, tomando el período, el GPT se ha multiplicado por 2: creció el 100\%. Se muestran dos caídas bruscas: en 1982 cae el 20\%, y en 2002 el 38\%. Luego, se observa un declive paulatino entre 1987 y 1990: en total, en esos 3 años cae el 25\%. Aun más, en 2002 el GPT era el 20\% inferior que al comienzo del período, y todavía en el año 2004 estaba por debajo de 1980. Efectivamente, la multiplicación del GPT se produce entre 2002 y 2008 , cuando crece el $150 \%$, pasando de 60 mil millones de pesos a 150 mil millones, aproximadamente.

Es posible observar que el recorrido del GPT y el GPS es casi idéntico. Este último creció el 150\% en el período. Sus caídas acompañan a las del GPT. Pero conviene hacer una serie de observaciones. Como se ha dicho, el GPT cae el 20\% en 1982, mientras el GPS cae el 34\%. Aquí el GPS es el que sufre el desplome, mientras se paga más deuda que en los años anteriores y los otros dos rubros casi no sufren el declive. Contrariamente, entre 1987 y 1990, el GPT cae el 25\%, mientras el GPS sólo el 15\%. Luego, en 2002 el GPT cae el 38\%, y el GPS el 32\%. Vale decir: ante crisis profundas, el GPS asume las consecuencias, pero cada vez menos.

Luego, el GPS pasó de absorber el 49,9\% del GPT en 1980, al 62,9\% en 2008. Es decir, el GPS constituye casi las dos terceras partes del GPT. El porcentaje que asume en 2008 no es el mayor del período. De hecho en la década del 90, a excepción de los dos primeros años, la participación del GPS en el GPT es mayor que en el primer decenio del 2000. En el '94, por ejemplo, es mayor al 66\%. De todos modos hay que considerar que, en términos absolutos, el actual es enormemente mayor. Tomando el período en su extensión, el GPS gana participación frente a los demás destinos generales del GPT.

En cuanto a FE, lo que sucede es que crece en términos absolutos (casi el 90\%), pero en términos de participación en el GPT se mantiene prácticamente constante. En efecto, en todo el período prácticamente no ha bajado del 15\% ni superado el 20\%. De nuevo, es durante la década del ' 90 donde alcanza los porcentajes de participación más altos: en 1999 implica el 19,3\% del GPT. En síntesis, el GPT cae el 20\% en 1982, el 25\% entre 1987 y 1990, y un escandaloso 38\% en 2002. Pero hay más: no sólo cae en términos absolutos, sino que incluso pierde participación en el mermado PBI. El PBI cae, pero el Gasto cae más aún. Así, en 1981, el Gasto total significa el 31,4\% del PBI, en 1983: el 26\%; en 1987: el 34,6\%; en 1990: el 30\%. En 2001: el 35,7\%; en 2002: el 29,2\%.

Lo anterior significa que, en momentos de crecimiento económico, la curva ascendente del gasto público es más pronunciada que la del PBI. Contrariamente, ante cada crisis el gasto pierde peso relativo en el PBI, o sea que la curva descendente también es más pronunciada en momentos de contracción. Ahora bien, esto último parece contradictorio con la hipótesis planteada: el Estado crece. Efectivamente, en términos históricos, lo que se muestra es que el Estado crece. Si se lo compara con el PBI, lo que resulta es lo siguiente: el Gasto estatal total significa el 31,4\% del PBI en 1981; el 34,6\%

Para citar este artículo:
Cristeche, M. (julio - diciembre 2012). Menemismo y kirchnerismo frente al gasto estatal en educación y seguridad. Ánfora 19 (33), 31-49. Universidad Autónoma de Manizales. ISSN 0121-6538. 
en 1987; el 35,7\% en 2001. En 2008 alcanza el 38,5\% del PBI, récord en el período. El techo, en la antesala de cada crisis, es cada vez más alto. Pero, paralelamente, el piso al que cae es cada vez más bajo.

\section{El Gasto Público en Educación.}

La fuente utilizada tiene una denominación más extensa: Educación, Cultura y Ciencia y Técnica (en adelante educación o ECCyT salvo indicación expresa), que incluye a su vez cinco sub-rubros: a) Educación básica; b) Educación superior y universitaria; c) Ciencia y Técnica; d) Cultura; y e) Educación y cultura sin discriminar.

Para comprender la magnitud de educación es necesario encuadrarlo junto a los demás rubros del destino GPS. En el gráfico 4, se indica el grado de participación porcentual de cada uno en el GPS.

\section{Gráfico 4}

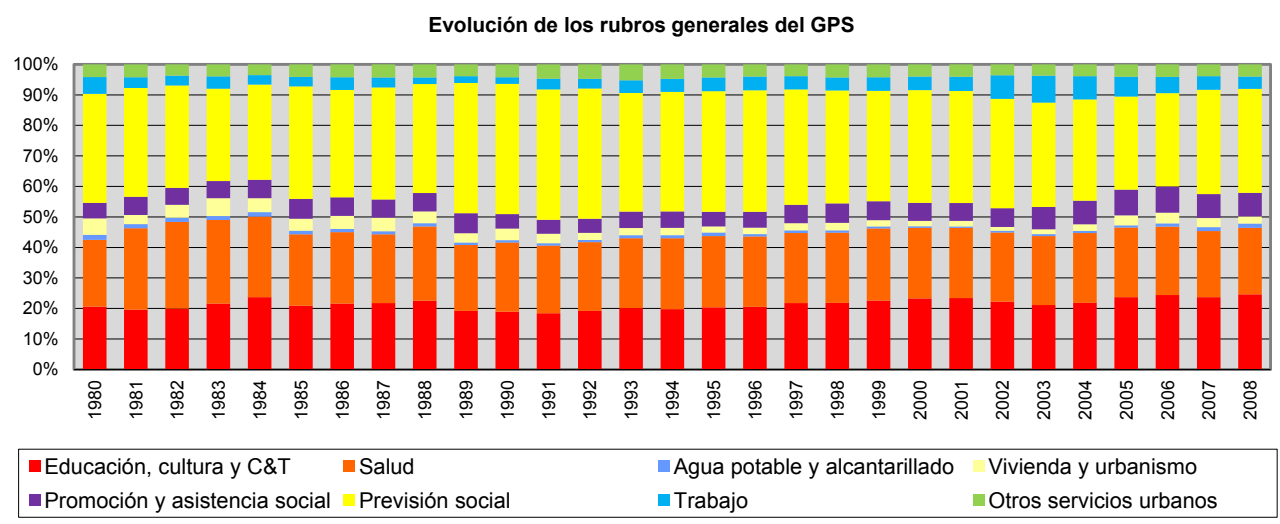

Fuente: elaboración propia con base en datos de la Secretaría de Política Económica, MEcon.

ECCyT se ubica en el segundo lugar de importancia, luego de Previsión Social (PS) que es el rubro con mayor participación en el GPS, con un promedio del 35\% de absorción durante el período. En tercer lugar está Salud (S), que históricamente era el segundo. Salud se mantuvo constante, con un promedio del $22 \%$ de participación, mientras que ECCyT ha crecido del 20 al 24\%. Estos 3 rubros generales sumados significan el $80 \%$ del GPS.

Educación crece lentamente, y sobremanera a partir de 2004 (el 100\% hasta 2008).

A continuación el Gráfico 5 muestra la participación de cada sub-rubro de educación. 


\section{Gráfico 5}

ECCyT discriminado por sub-rubros (en \%)

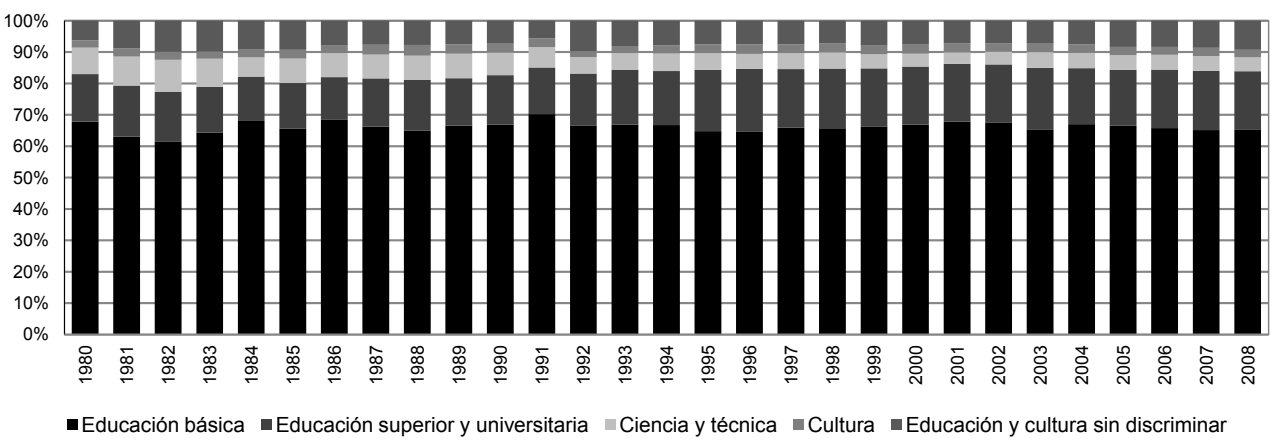

Fuente: elaboración propia con base en datos de la Secretaría de Política Económica, MEcon.

En su composición interna, es evidente el predominio de Educación básica, que se ha mantenido en todo el período entre el 60 y el 70\% de ECCyT, seguido por Educación superior y universitaria $(18,6 \%)$. Siendo que estos dos sub-rubros concentran más del $83 \%$ de educación, y en consecuencia los otros tres son prácticamente marginales, se prestará mayor atención a aquéllos.

En el gráfico 6 se puede observar la evolución de la participación de ECCỹ y de sus dos componentes más importantes en el PBI.

\section{Gráfico 6}

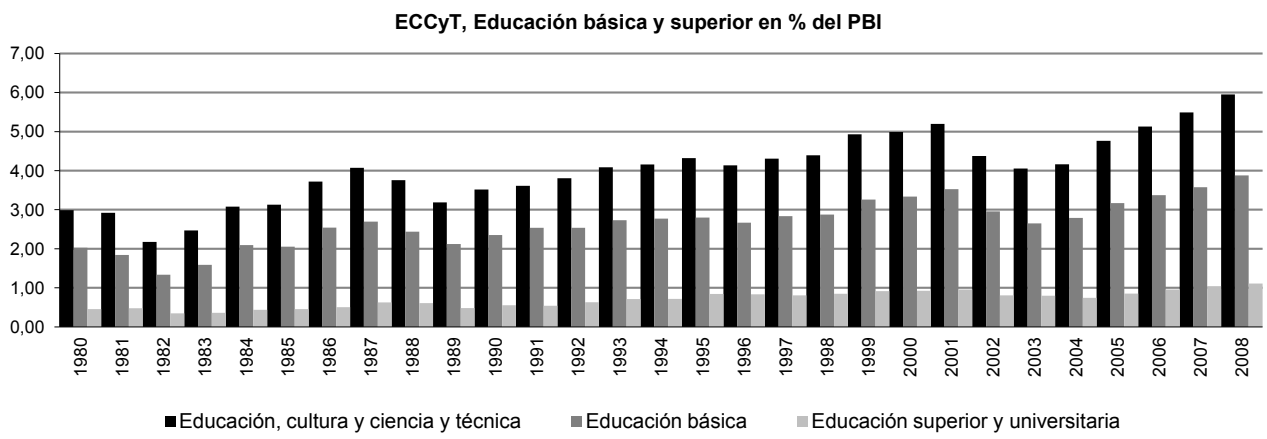

Fuente: elaboración propia con base en datos de la Secretaría de Política Económica, MEcon.

El punto de partida de ECCyT es el 3\% del PBI en 1980. Sólo en los 3 años que le siguen (1981-1983), crisis económica de por medio, el porcentaje de participacion es menor: 2,18\% en 1982. Luego, crece hasta que se topa con una nueva crisis. En efecto,

Para citar este artículo:
Cristeche, M. (julio - diciembre 2012). Menemismo y kirchnerismo frente al gasto estatal en educación y seguridad. Ánfora 19 (33), 31-49. Universidad Autónoma de Manizales. ISSN 0121-6538. 
en 1987 alcanza el 4\%; en 1989, cae al 3,15\%. En 2001 supera el 5\%; en 2003, cae al $4 \%$. Es decir, casi un punto por cada crisis, lo que significa una disminución del $25 \%$ en relación con el PBI. Pero siempre su piso, al igual que su techo, es más alto. Dicho de otra manera: en términos históricos, crece. Desde 2003 a esta parte creció casi 2 puntos. En 2008 es casi el 6\% del PBI, el porcentaje más alto registrado. Ello significa que su participación en el PBI ha crecido, desde 1980 a 2008, un 100\%.

En cuanto a Educación básica, comienza el período con una participación del 2\% del PBI. Asimismo, muestra un movimiento similar al rubro general en momentos de crisis. En 2008, está cerca del 4\%, su máximo grado de participación y su crecimiento ronda el 100\%. La participación de Educación superior y universitaria recién en 2008 logra superar el 1\% del PBI. Al inicio del período, su participación es del 0,45\%. Ello significa que su participación se incrementó en casi el 150\%.

Ahora se observa, con el Gráfico 7, la evolución de los sub-rubros a valores constantes.

\section{Gráfico 7}

Evolución de los Rubros de ECCyT (a valores constantes)

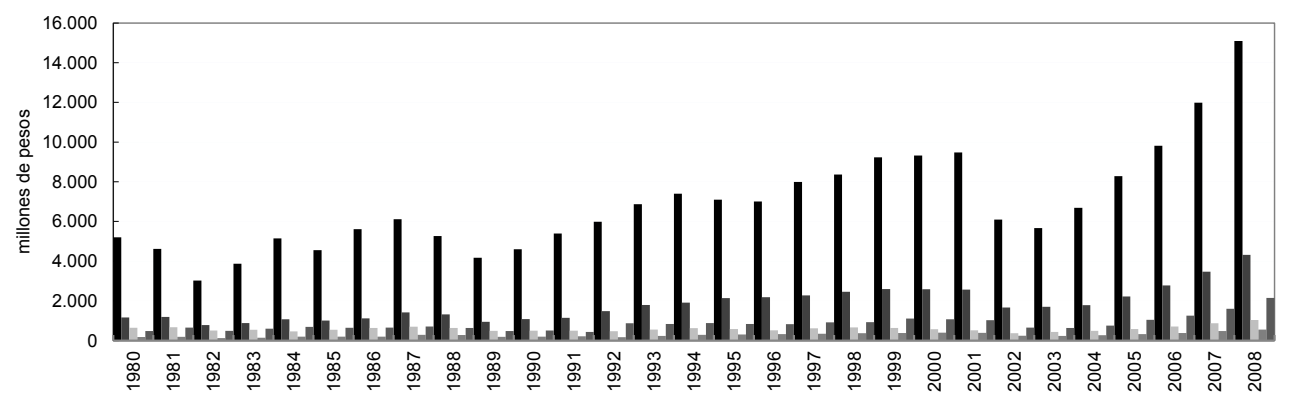

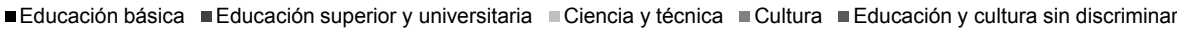

Fuente: elaboración propia con base en datos de la Secretaría de Política Económica, MEcon.

Este gráfico muestra el incremento del gasto en educación en su conjunto y, particularmente, en educación básica y superior y universitaria. En 1980, el gasto en educación básica es de unos 5.200 millones de pesos. Al final del período, en 2008, es aproximadamente 15.000 millones. Ello equivale a un crecimiento aproximado al $200 \%$. Educación básica se ha multiplicado por 3. Por su parte, Educación superior y universitaria inicia el período con un gasto de 1.164 millones de pesos, y lo cierra con 4.321 millones. Ha crecido más del $250 \%$. Luego, para lo que aquí interesa, es evidente que en los '90 el Estado no "desapareció" de la Educación, porque recién en 2006 se superan los valores de 1999, 2000 y 2001. 
También puede observarse otro fenómeno, que ha sido confundido con la retirada del Estado: la descentralizacion de la funcion educativa. Eso quiere decir que las provincias han asumido un peso cada vez mayor en el gasto educativo, con el correspondiente achique del gasto nacional. En el gráfico 8 puede evidenciarse que la participacion del Estado nacional y las provincias era similar al comienzo del período. Ya desde mediados de la década del ' 80 comienza el fenomeno apuntado, y se desarrolla con fuerza en 1992. A partir de allí se mantiene constante: las provincias asumen entre el 75 y el 78\% del gasto educativo, mientras que Nación entre el 18 y el 25\%. El resto, una ínfima parte, es responsabilidad de los municipios.

\section{Gráfico 8}

\section{ECC\&T según repartición}

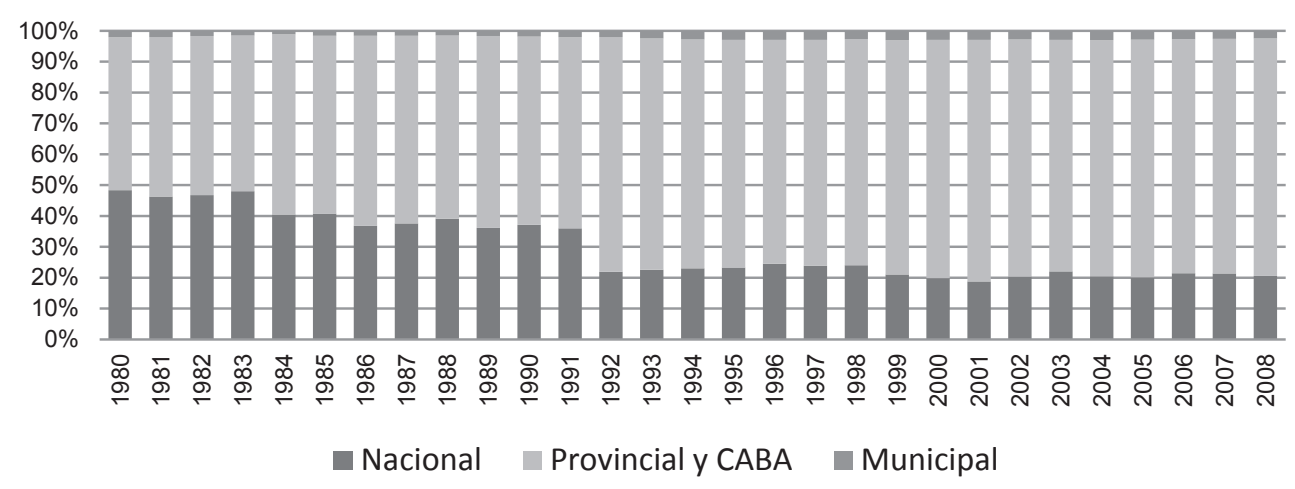

Fuente: elaboración propia con base en datos de la Secretaría de Política Económica, MEcon.

\section{Gráfico 9}

\section{Participación de DyS en el PBI (en \%)}

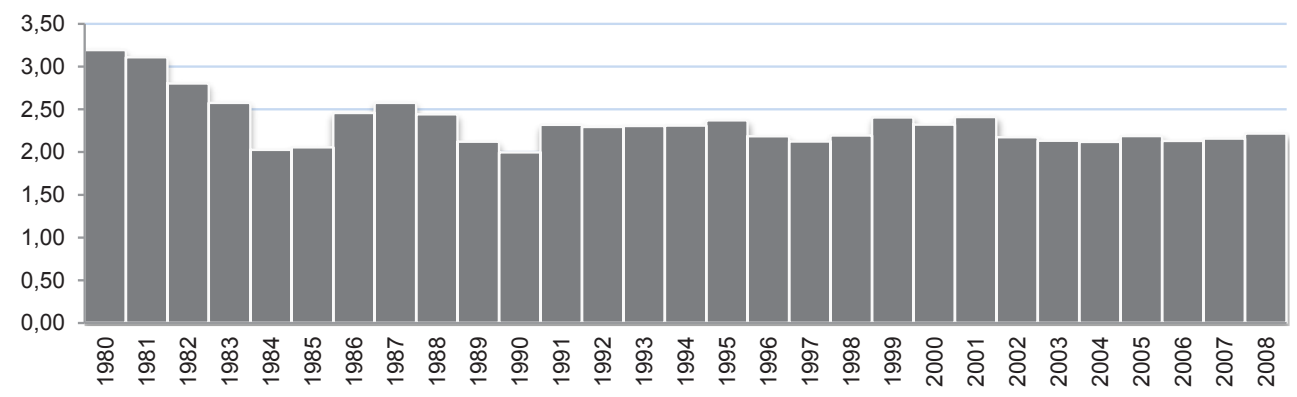

Fuente: elaboración propia con base en datos de la Secretaría de Política Económica, MEcon. 


\section{El Gasto Público en Defensa y Seguridad.}

Se dijo que el rubro Defensa y Seguridad (DyS) se encuentra dentro del destino general Funcionamiento del Estado -cuya participación ha oscilado entre el 4 y casi el 7\% del GPT, junto a los gastos en Administración general y en Justicia. En primer lugar, hay que observar la participación de DyS en el PBI (Gráfico 9)

Es evidente que la participación de DyS en el PBI ha disminuido en el período. Cayó un punto del PBI. Es, en estos términos, un tercio más chico que al comienzo. Es cierto que el punto de partida lo constituyen años de Gobiernos de Facto pero, de todos modos, ni siquiera en 2008 ha recuperado la participación que tuvo, por ejemplo, durante los últimos años del alfonsinismo. Es entre 1980 y 1984 que alcanza su techo y su piso, respectivamente. De allí en adelante, amén de perceptibles movimientos, se ha mantenido constante, entre el 2 y el 2,5\% del PBI. Durante el menemismo tuvo dos pequeñas recaídas, sobre todo al inicio, con la crisis del 89; sin embargo, culmina el período con casi medio punto de crecimiento, lo cual, en el marco de la tendencia descripta, es llamativo. En el caso del kirchnerismo, como es fácilmente advertible, se mantiene invariable.

También se apuntó anteriormente que la participación de FE en el PBI no ha decrecido en el período, sino que se ha mantenido prácticamente constante, con un leve crecimiento. Ello quiere decir que si, como se vio, DyS pierde peso histórico, otros rubros de FE crecen. El gráfico 10 muestra con claridad tal situación.

\section{Gráfico 10}

\section{Evolución de los rubros del GFE}

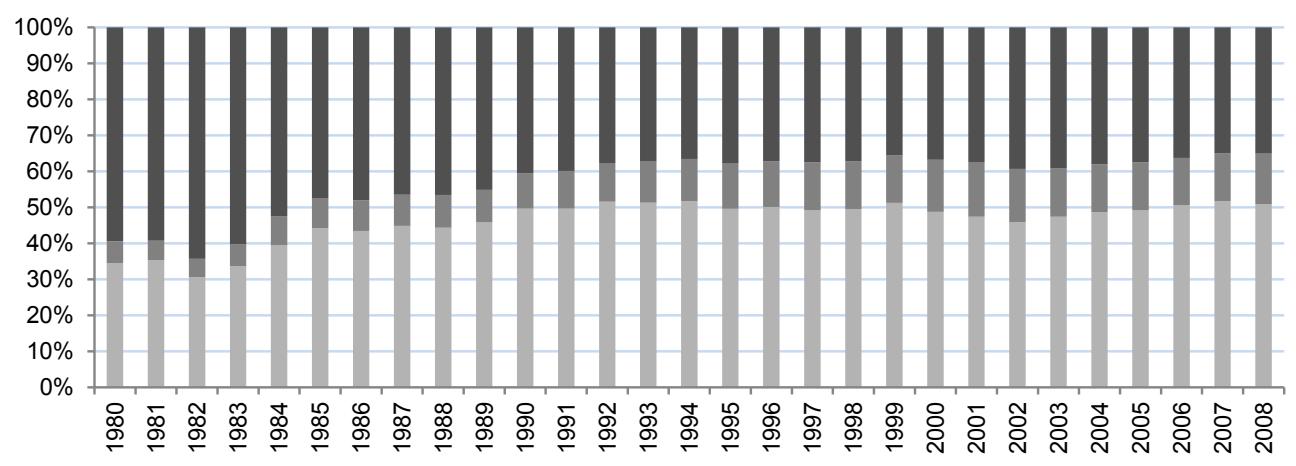

\section{administración general = Justicia $\quad$ Defensa y seguridad}

Fuente: elaboración propia con base en datos de la Secretaría de Política Económica, MEcon.

Es el rubro administración general (AG) el que se lleva la importancia que tenía DyS al comienzo del período. En 1980, DyS absorbe el 60\% del gasto en FE (en 1982 alcanza su pico del 65\%), mientras que al final del período apenas llega al 35\%. En 
sentido inverso, AG pasa del 35\% al 50\%. La diferencia es compensada con un sensible incremento del rubro justicia.

Por otra parte, también en el caso de DyS se da el mismo fenómeno que en educación: la descentralización del gasto. Como se muestra en el gráfico 11, el peso relativo de las provincias frente al Estado nacional es cada vez mayor. Hasta 1989, por lo menos el 70\% del gasto estatal en DyS era asumido por la repartición nacional. A partir de allí se evidencia una caída paulatina y sostenida, que sólo se corta, llamativamente, en los años 2002 y 2003. Luego, desde 1993 la participación de las provincias en el gasto es superior al 40\%, y desde el 2005 las provincias gastan más en DyS que nación.

\section{Gráfico 11}

\section{Gasto Público en Defensa y seguridad según repartición}

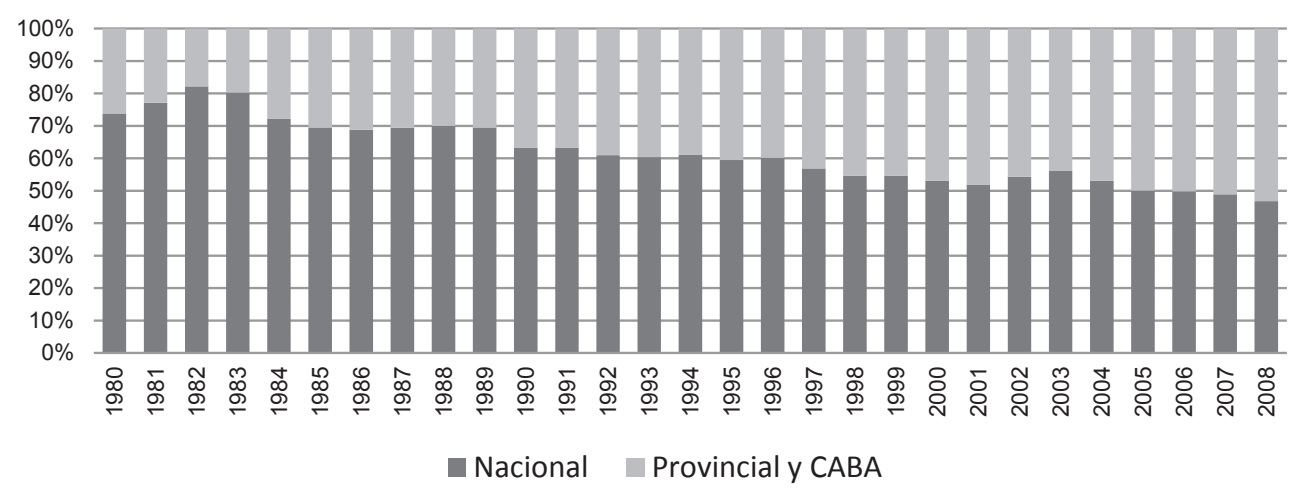

Fuente: elaboración propia con base en datos de la Secretaría de Política Económica, MEcon.

\section{Gráfico 12}

ECCyT y Defensa y seguridad en \% del PBI

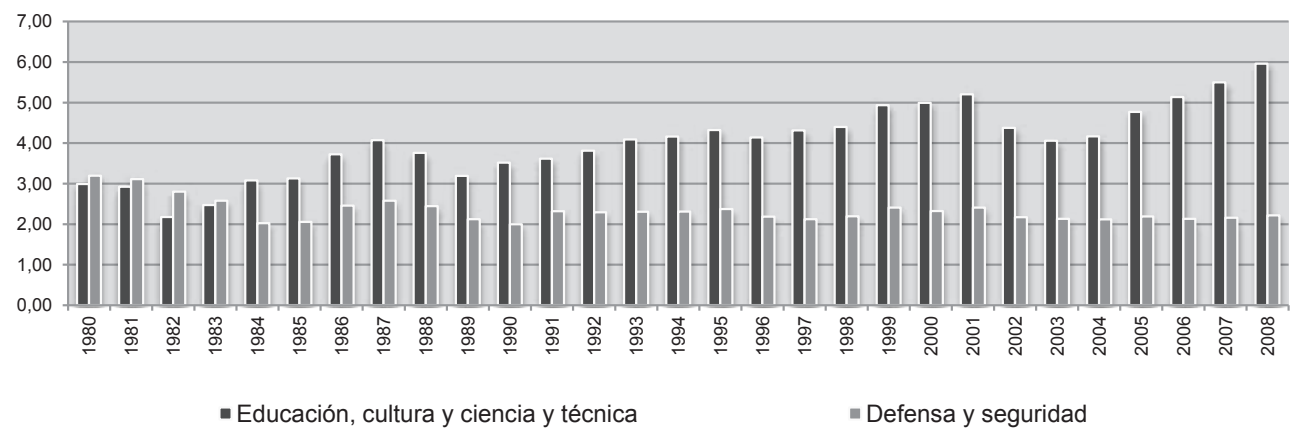

44 Fuente: elaboración propia con base en datos de la Secretaría de Política Económica, MEcon. 
Se impone un último ejercicio: comparar directamente los aparentes antagónicos: ECCyT y DyS. No se cuenta con mejor instrumento de comparación que la participación de cada uno en el PBI a lo largo del período (Gráfico 12).

Como puede observarse, en los primeros años hay cierta paridad de participación, con algún predominio de DyS, sobre todo en 1982, en que es $22 \%$ mayor a educación. Luego, a partir de 1984, educación crece sostenidamente, a punto tal que para fines de la década del 90 es dos veces mayor a defensa y seguridad, que a su vez muestra un estancamiento, e incluso una declinación. Así, su participación al comienzo del período $(3,2 \%)$ es su techo, y en el 2008 , como se dijo, apenas supera el $2 \%$ del PBI. Ha decrecido casi un tercio. La evolución de educación es exactamente la contraria. Los números de comienzos del período son los más bajos. En 2008 su participación en el PBI es el triple que la de Defensa y Seguridad.

Por último, la comparación a valores constantes, hará más evidente lo apuntado (Gráfico 13).

\section{Gráfico 13}

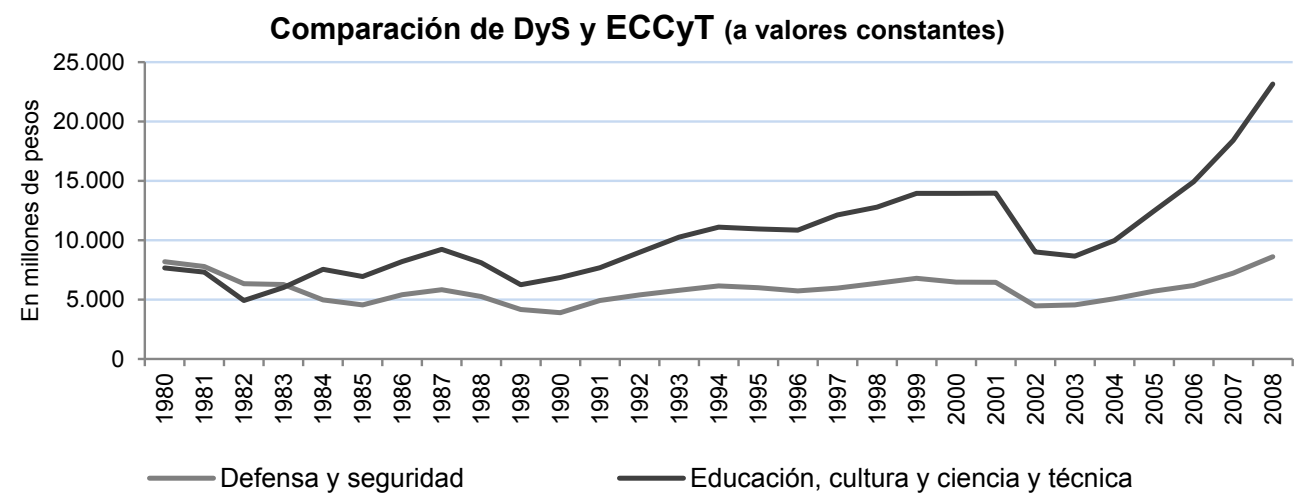

Fuente: elaboración propia con base en datos de la Secretaría de Política Económica, MEcon.

El punto de partida es casi el mismo; hasta 1983 el Estado gasta más en DyS que en ECCyT. Por su parte, DyS puede alcanzar los valores de 1980 en el último año del período, 2008. Educación, por el contrario, crece sostenidamente, aunque hay que apuntar que las crisis golpean el Gasto educativo. En efecto, en 1982 registra los valores más bajos; en 1989 retrocede a 1984; en 2002 y 2003 es menor que en 1987. Luego, en 2008 es 3 veces mayor a 1980 . 


\section{Conclusiones}

A lo largo de estas páginas se ha tratado de dar luz sobre ciertos fenómenos vinculados con la realidad económica y política argentina. Va de suyo que la intención no ha sido agotar la discusión sobre las cuestiones abordadas. Todo lo contrario: está la claridad de que se requiere analizar otras determinaciones que permitan tener un conocimiento más profundo sobre la evolución de la educación y la seguridad estatales en la era democrática. De todos modos, el aporte que se ha hecho aquí puede servir para avanzar en tal objetivo.

Los prejuicios ideológicos no son buenos amigos de la ciencia. Y si hay algo que ha llamado la atención al realizar este trabajo, es que las opiniones dominantes sobre el tema presentan las determinaciones invertidas, con objetivos puramente ideológicos, y sin preocuparse por el análisis concreto. Es decir, se trataría de "modelos" diferentes, siendo las estrategias políticas las que determinan el curso que ha de seguir la acción del Estado, y, particularmente, el gasto público. Así, se construyen "relatos" que mutilan del análisis la base material de toda la discusión: el proceso de acumulación de capital en Argentina, sus momentos de expansión, de estancamiento y de retracción, que determinan la acción política del Estado y de las clases sociales. En consecuencia, esta compleja realidad aparece reducida a un problema de "modelos".

En el caso de la educación, como se ha dicho al comienzo, cualquier transformación del Estado que haya implicado su "retirada" debiera haberse visto reflejada en el gasto estatal. No se está diciendo que aquí está toda la cuestión, pero de alguna manera este factor debe dar cuenta de tan drástico cambio. Por el contrario, lo que se observa es que el gasto estatal en educación ha crecido, y la magnitud de su crecimiento es importante. Que haya multiplicado por 3 su participación en el PBI, es un hecho insoslayable.

El presente análisis no pretende redundar en una loa a la educación argentina. El crecimiento de las partidas presupuestarias poco dice de la calidad de la educación y de las necesidades a las que responde. Pero lo que sí dice, es que en los 90 no hubo una "retirada" en cuanto al financiamiento del Estado, y por lo tanto esa antítesis construida entre "Estado ausente" y "Estado presente" arriba a una falsa discusión.

El caso de la defensa y la seguridad, desde la perspectiva de este análisis, requiere una complejización mucho mayor de la que se ha hecho aquí. Más que en el caso de la educación, lo dicho debe considerarse como provisorio, y seguramente será sujeto a un estudio más riguroso en un futuro cercano. De todos modos, algunos resultados muestran cierta contundencia: el gasto en DyS ha caído, y pierde peso relativo frente a otros rubros; la educación y la administración general son dos de ellos.

La descentralización es un fenómeno que atañe tanto a educación como a defensa y seguridad (De Luca, 2008; Seiffer, 2011). Precisamente, es una de las determinaciones

46 que será necesario complejizar. El gasto público depende de la capacidad recaudatoria

Para citar este artículo:
Cristeche, M. (julio - diciembre 2012). Menemismo y kirchnerismo frente al gasto estatal en educación y seguridad. Ánfora 19 (33), 31-49. Universidad Autónoma de Manizales. ISSN 0121-6538. 
del Estado y, por tanto, de la situación general de la economía. La observancia de los períodos de crisis económica, y la correspondiente caída del gasto público, manifiesta que no tiene un comportamiento anti-cíclico.

Por otro lado, se insiste en que el Estado no desapareció en los 90, ni mucho menos. Al contrario: a pesar de ciertas anomalías, creció. Esa creencia de que el "neoliberalismo" de los 90 ("herencia de la dictadura") es la causa de todos los males, no es más que un viejo y conocido recurso ideológico que pretende negar, intencionadamente, la discusión sobre el verdadero problema, que es el modo capitalista de producción y organización de la vida social.

Otro prejuicio ideológico que nunca pasa de moda es aquel que atribuye los malos vientos -y los buenos, por supuesto- a la abstracta voluntad política de un fulano. Así, en los últimos años el expresidente Menem, responsable de todo, se ha convertido en el chivo expiatorio para que las influyentes fuerzas progresistas renueven su confianza -otrora desgastada- en las potencias del modo de producción capitalista para resolver los grandes problemas sociales en el ámbito nacional, ahora bajo el 'modelo K'.

El Estado se ha esforzado, en el período analizado, por asumir un papel cada vez más relevante, y de hecho lo ha logrado. Pero también es evidente que el gasto estatal se desploma ante cada crisis. El problema central no son los gobiernos ni su voluntad, sino la base sobre la que se asienta el gasto estatal: la economía argentina y ésta como expresión de la unidad mundial del proceso de acumulación de capital.

La situación actual de los principales Estados del mundo -incluidos los estados europeos y EEUU- dan cuenta de las imposibilidades de un recorte nacional para sortear las consecuencias de la crisis capitalista. Es el propio desenvolvimiento del modo de producción capitalista -y específicamente sus inherentes períodos de crisisel que marca a fuego los límites históricos del intervencionismo estatal propiamente capitalista. Este es, en consecuencia, el eje que debe ordenar una discusión que supere las apariencias.

\begin{tabular}{l|l} 
Para & Cristeche, M. (julio - diciembre 2012). Menemismo y kirchnerismo frente al gasto estatal
\end{tabular} 


\section{Referencias}

Basualdo, E. (2010). Estudios de historia económica argentina: desde mediados del siglo XX a la actualidad. Buenos Aires, Siglo XXI Editores.

Basualdo, E. (2002). Concentración y centralización del capital en la Argentina durante la década del noventa. Buenos Aires, FLACSO, Universidad Nacional de Quilmes.

Bonari, D. (2007). La medición del Gasto Social en la Argentina: avances y desafíos metodológicos. Buenos Aires, Dirección de Análisis de Gasto Público y Programas Sociales, Ministerio de Economía y Producción. Disponible en http://www.cepal. org/dds/GastoSocial/docs/ppt_DBonari_Arg.pdf

Boyer, Robert y J. Neffa (comp.) (2004). La economía argentina y su crisis (1976-2001): visiones institucionalistas y regulacionistas. Buenos Aires, Miño y Dávila.

Bulacio, J. (2003). Causas del crecimiento del Gasto Público. Buenos Aires, Asociación Argentina de Economía Política.

Bulacio, J. (2000). La ley de Wagner y el Gasto Público en Argentina. Córdoba, Asociación Argentina de Economía Política.

Cristeche, M. (2012). “Estado, gasto público y formas jurídicas. Nociones sobre el sistema presupuestario argentino", en Revista Derecho y Ciencias Sociales, N 7.

Cristeche, M. (2010). Desesperado. El Gasto Público Social en Argentina (1980-2008). En Razón y Revolución No 20. Buenos Aires, Ediciones RyR.

Cristeche, M. (2010b). Los números de la educación argentina. Gasto estatal en educación. 1980-2008. En Anuario del CEICS No 3, año 2010.

De Luca, R. (2008). Brutos y baratos: descentralización y privatización en la educación argentina: 1955-2001. Buenos Aires, Ediciones RyR.

Ferreres, O. (Dir.) (2011). Dos siglos de economía argentina. 1810-2010. Buenos Aires, Fundación Norte y Sur.

Filc, G. (2008) (Comp.). Las políticas fiscales en la Argentina: un complejo camino hacia la equidad y la eficiencia. Buenos Aires, Fundación CIPPEC.

Koenig, M. (2009). Combatiendo al capital. Una perspectiva sudamericana del estado nacional en los tiempos de la globalización y la exclusión. La Plata, De la Campana.

Oszlak, O. (2002). Privatización y capacidad de regulación estatal: una aproximación teórico-metodológica. Buenos Aires, CLAD.

48 Oszlak, O. (2009). La formación del estado Argentino. Buenos Aires, Emece. 
Seiffer, T. (2010). La Política Social argentina en los '90: de forma y de contenido. En Revista Serviço Social e Contemporaneidade no 9, año 2010, ISSN no: 1676-1707.

Seiffer, T. (2011). La miseria del capital. El papel de la política social en la reproducción de la sobrepoblación relativa. Tesis de doctorado. Buenos Aires, FCS, UBA. Inédita.

Selva, R e Iñiguez, A (2009). "Descripción de la evolución del Gasto Público Consolidado del Sector Público Argentino (1980-2008)". Documento de Trabajo. Subsecretaría de Programación económica, Secretaría de Política Económica, MEcon.

Toledo, F. y J. C. Neffa (Coord) (2008). Interpretaciones heterodoxas de las crisis económicas en Argentina y sus efectos sociales. Buenos Aires, Miño y Dávila.

Thwaites Rey, M. (1999). "Estado y sociedad. Ajuste estructural y reforma del Estado en la Argentina de los '90”. Buenos Aires, Revista Realidad Económica Nro. $160 / 1$.

Thwaites Rey, M. (2003). La (des)ilusión privatista. El experimento neoliberal en Argentina. Buenos Aires, Eudeba.

\begin{tabular}{l|l} 
Para & Cristeche, M. (julio - diciembre 2012). Menemismo y kirchnerismo frente al gasto estatal
\end{tabular} 